2 Article Type: Main Research Article

3 Feasibility of using self-reported ethnicity in pregnancy according to the Gestation

4 Related Optimal Weight (GROW) classification: a cross-sectional study

5

6 Short title: Reliability of self-reported ethnicity in pregnant women

Elizabeth Lockie

10 Mercy Perinatal, Mercy Hospital for Women, Melbourne, Australia

11 Department of Obstetrics and Gynaecology, University of Melbourne, Australia

Elizabeth McCarthy

14 Senior Lecturer

15 Mercy Perinatal, Mercy Hospital for Women, Melbourne, Australia

Department of Obstetrics and Gynaecology, University of Melbourne, Australia

Lisa Hui

Associate Professor of Maternal Fetal Medicine

Mercy Perinatal, Mercy Hospital for Women, Melbourne, Australia

Department of Obstetrics and Gynaecology, University of Melbourne, Australia

\title{
Leonid Churilov
}

24 Professor and Head, Statistics and Decision Analysis Academic Platform,

Florey institute of Neuroscience and Mental Health, University of Melbourne, Australia

\section{Susan P Walker}

Professor of Maternal Fetal Medicine

Correspondence: Susan Walker, Department of Perinatal Medicine, Mercy Hospital for Women,

This is the author manuscript accepted for publication and has undergone full peer review but has not been through the copyediting, typesetting, pagination and proofreading process, which may lead to differences between this version and the Version of Record. Please cite this article as doi: 10.1111/1471-0528.14825

This article is protected by copyright. All rights reserved 


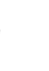

(2)

5

(O)

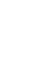

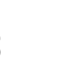

9

1

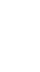

3

55

56

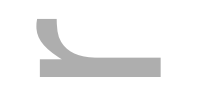

\section{Abstract}

57 Objective

58 To evaluate the feasibility of self-reported ethnicity using the Gestation Related

59 Optimal Growth (GROW) classification in a contemporary multicultural antenatal

60 population.

61 Design

62 Cross-sectional study

63 Setting

64 Tertiary obstetric hospital in Melbourne, Australia

65 Population

66 Pregnant women attending antenatal clinic

67 Methods

This article is protected by copyright. All rights reserved 
We surveyed pregnant women during April-June 2016 regarding their understanding of the term 'ethnicity', and how they would classify the ethnicity of themselves, their partner and family members according to the Australian

71 GROW classification.

72 Results

73 Two hundred and thirty five women completed the survey. When describing

74 'ethnicity', most women 103 (44\%) chose multiple descriptors, most frequently country of birth (54\%) and region of ancestry (47\%). Interpretation of 'ethnicity' varied significantly between ethnic groups; those choosing 'country of birth' were more likely to identify as Indian (OR 3.5, p=0.03), whereas those choosing 'physical appearance' were more likely to identify as Chinese (OR 3.0, p=0.047). Thirty participants (13\%) were unable to describe their ethnicity from the available GROW options. Sixty-one (26\%) respondents' ethnicity was inconsistent with that of their parents' heritage. A further $35 \%$ had a partner of different ethnicity. The agreement between country of birth and self-reported ethnicity was only fair (kappa 0.73 (95\%CI 0.64-0.82)).

\section{Conclusions}

85 This study confirms the complexity of defining ethnicity in contemporary multicultural settings. Self-reported ethnicity is often inaccurate, concepts of ethnicity vary by ethnic group and country of birth is a poor descriptive surrogate. Adjustment for maternal ethnicity should be undertaken with caution in the customised assessment of fetal growth.

90 Funding: There has been no external funding for this study and we have no

91 financial interests to declare

92 Key words: growth restriction, small for gestational age, ultrasound, estimated 93 fetal weight, customised fetal growth, ethnicity

94 Tweetable abstract: Is self-reported maternal ethnicity reliable? We think not. 


\section{List of abbreviations used}

GROW Gestation Related Optimal Weight

FGR Fetal growth restriction

SFH Symphysis-fundal height

US Ultrasound

SGA Small for gestational age

GA Gestational age

BMI Body mass index

AFI Amniotic fluid index

EFW Estimated fetal weight

\section{Introduction}

111 A major goal of antenatal care is the detection of fetal growth restriction (FGR), a

112 leading risk factor for stillbirth ${ }^{1-3}$ and long term morbidity ${ }^{4,5}$. Antenatal

113 identification of the small for gestational age (SGA) fetus has been shown to

114 reduce the risk of stillbirth ${ }^{1}$, yet an ongoing clinical challenge is differentiating

115 the constitutionally small from the growth restricted. Improved identification of

116 the pathologically small forms the basis of the Gestation Related Optimal Weight

117 (GROW) customised growth charts developed by Gestation Network ${ }^{6}$. GROW

118 customised centiles adjust the ultrasound-derived estimated fetal weight (EFW),

119 or birthweight, for maternal height, weight, ethnicity, parity and fetal gender, in

120 order to better identify those fetuses that have deviated from their genetic

121 growth potential.

123 The validity of adjusting fetal growth standards according to maternal ethnicity

124 is controversial. It has been suggested that smaller birthweights among some 
125 ethnic groups may reflect socio-economic disadvantage rather than reduced

126 genetic potential 7,8, and thus adjusting fetal growth expectations for these

127 groups runs the risk of adjusting to perinatal disadvantage. Further, the

128 precision of a mathematical adjustment for ethnicity is undermined by the fact

129 there is no 'gold standard' for defining ethnicity. This is evidenced by British

130 guidelines that state that ethnicity encompasses "common ancestry and elements

131 of culture, identity, religion, language and physical appearance", and that

132 emphasise the "subjective, multifaceted and changing nature of ethnic

133 identification"9.

Added to these concerns is that the feasibility and reliability of assigning ethnicity according to the pre-specified categories available in the GROW algorithms (see Appendix S1), has not been previously tested in a multicultural antenatal population. This is the focus of the current study.

Methods

This cross-sectional study was conducted between April and June 2016. It involved a convenience sample of 240 women attending antenatal clinics in a public tertiary obstetric hospital in Melbourne, Australia. This hospital is responsible for nearly 6,000 births annually; 38\% of maternity patients are born overseas, $20 \%$ primarily speak a language other than English ${ }^{10}$, and $4 \%$ of patients require the services of an interpreter 11.

Respondents' names were randomly selected by time of arrival to the antenatal clinic waiting room, to minimise selection bias. They were administered an online secure survey using SurveyMonkey ${ }^{\circledR}$ while waiting for their

152 appointment. The survey (see Appendix $S 2$ for full survey) asked women what 153 they understood of the term 'ethnicity', choosing at least one descriptor from a 154 list including language, religion, country of birth, physical appearance, region of 155 ancestry, country of citizenship and other. They were then asked to state their 156 ethnicity, choosing from the 25 available options for the Australian population 157 provided by Gestation Network in the GROW software (Appendix S1). As per the 
GROW software, no definition of 'ethnicity' was provided. Given the Australian

159

160

161

162

163

164

165

166

167

168

169

170

171

172

173

174

175

176

177

178

179

180

181

182

183

184

185

186

187

188

\section{Results}


190 Of 240 women attending antenatal clinic, 235 (98\%) agreed to participate. Sixty-

191 seven (29\%) participants reported speaking English as a second language, but

192 none required the services of an interpreter.

193

\section{Pregnant women's understanding of 'ethnicity'}

195 When asked to define 'ethnicity', the most common answer provided was 196 country of birth ( $\mathrm{n}=128,54 \%$ (95\% confidence interval (CI) 48-61\%)), followed 197 by region of ancestry ( $\mathrm{n}=111,47 \%$ (95\% CI 41-54\%)). Language, religion, 198 physical appearance and country of citizenship were included in the responses of $19923 \%$ (95\% CI 17-28\%), 20\% (95\% CI 15-26\%), 16\% (95\% CI 11-21\%) and 11\% 200 (95\% CI 7-16\%) of women respectively (Figure 1). Nearly half (n=103, 44\% 201 (95\% CI 37-50\%)) of respondents chose more than one descriptor.

\section{Variations in interpretation of 'ethnicity' by self-reported ethnicity}

How women described 'ethnicity' varied significantly according to their selfreported ethnicity. Figure 2 demonstrates the varied response to the descriptors in the three main ethnic groups in the study population - Australian European $(\mathrm{n}=92,40 \%(33-46 \%))$, Indian $(\mathrm{n}=19,8 \%(5-13 \%))$ and Chinese $(\mathrm{n}=19,8 \%(5-$ 12\%)). If a participant chose 'language' to describe ethnicity in the first question, she was significantly less likely to identify as Australian in the subsequent question (adjusted odds ratio 0.35 (95\% CI 0.16-0.74), p=0.006). If she chose 'country of birth' to describe ethnicity, she was over three times more likely to subsequently identify as Indian (aOR 3.5 (1.1-11.3), p=0.03). If she chose

214 Chinese (aOR 3.0 (1.0-8.9), p=0.047).

\section{GROW self-reported ethnicity}

217 When asked to describe their ethnicity according to the options provided in the 218 GROW program, 30 (13\% (8-17\%)) participants could not choose a single 219 ethnicity from the list, with 25 (11\% (7-15\%)) choosing 'mixed' and 5 (2\% (0220 4\%) choosing 'other'. Table 1 summarises the proportion of women who were 221 unable to choose a single ethnicity from the prescribed list to describe 222 themselves, the father of the baby (FOB), or their parents. 


\section{Self-reported ethnicity and pregnant women's family}

225 The participant's chosen ethnicity was inconsistent with the ethnicity she

226 assigned to her parents in 61 (26\% (20-32\%)) cases. This was either because the

227 ethnicities of her parents were different to each other (i.e. she was of mixed

228 ethnicity; $n=40,17 \%(12-22 \%)$ ), or because her parents were the same ethnicity

229 but she described herself as different $(n=21,9 \%(5-13 \%))$. This was commonly

230 because the participant chose Australian European for herself but Southern

231 European for both her parents.

232 In relation to her partner, 69 (35\% (28-41\%)) of participants described their

233 partner as a different ethnicity to themselves. One participant described herself

234 as Australian European and the father of the baby as Indian. If evaluated as

235 Australian European this baby would be on the $10.1^{\text {st }}$ percentile, whereas it

236 would be on the $16.3^{\text {rd }}$ percentile if evaluated as Indian, according to the GROW

237 software ${ }^{6}$ for $a$ for a $3000 \mathrm{~g}$ baby at 40 weeks to a nulliparous woman of average

238 height $(162 \mathrm{~cm})$ and booking weight $(71 \mathrm{~kg}){ }^{12}$.

\section{Self-reported ethnicity versus country of birth}

241 Country of birth is commonly used as a surrogate for ethnicity, yet participants'

242 self-described ethnicity was discordant with her country of birth in 42 (18\% (13-

$24323 \%$ )) cases. For example, one participant described herself as a mix of

244 Central/Western European and South East Asian, yet Australian-born. For the

245 cohort overall, the agreement between self-reported ethnicity and country of

246 birth was fair (kappa $=0.73$ (95\%CI 0.64-0.82)). All women describing

247 themselves as Australian European were born in Australia. However, only two

248 thirds of British Europeans were born in Britain, and one quarter of Southern

249 Europeans were born in Southern Europe. Many of the self-described Southern

250 Europeans were born in Australia $(n=12)$. The effect of choosing to describe

251 themselves as Southern European instead of Australian European on the

252 calculation of their baby's weight percentile would be 2.7 (12.8th versus 10.1th

253 percentile), as calculated using GROW software $^{6}$ for a $3000 \mathrm{~g}$ baby at 40 weeks to

254 a nulliparous woman of average height $(162 \mathrm{~cm})$ and booking weight $(71 \mathrm{~kg})^{12}$. 
Discussion

This study has identified challenges of feasibility when customising fetal growth according to self-reported maternal ethnicity in a multi-cultural population.

\section{Main findings}

264 A significant minority of women were unable to accurately describe their

265 ethnicity according to the GROW options available, most commonly because ethnicity was mixed. This is perhaps unsurprising in a multi-cultural society such as Australia with high rates of immigration and inter-ethnic marriage. In 2011, 29\% of women who gave birth in Australia were born overseas ${ }^{13}$. Similarly in the UK, $26 \%$ of women who gave birth in 2014 were born overseas ${ }^{14}$. Multi-cultural marriages comprised over half of marriages registered in Australia in 1998 (52\%), which was substantially higher than in 1974 $(39 \%)^{15}$. In the UK, $12 \%$ of marriages are inter-ethnic ${ }^{16}$. This means inaccuracies of classification will inexorably increase with time; over half of babies born to this cohort will themselves be classified as mixed ethnicity, because the ethnicity of the baby's mother is mixed (observed in 11\%), the ethnicity of the baby's father is mixed (seen in a further 12\%), or the mother and father are of different ethnicities (seen in 35\%). A recent study comparing genetic ancestry to selfreported ethnicity found that genetic admixture increases over time. Younger participants were more likely to have mixed self-reported ethnicity and mixed genetic ancestry, as a result of increasing exogamy over time ${ }^{17}$. While adjustment coefficients have been developed for some common combinations of ethnicities, it seems unlikely that coefficients of accuracy can be determined for the endless possibilities of mixed ethnicities.

This study has also unmasked differences and uncertainty in interpreting the term 'ethnicity'. There is no gold standard for the definition of ethnicity, with expert groups highlighting its subjective nature. The Australian Standard Classification of Cultural and Ethnic Groups (ASCCEG) ${ }^{18}$ defines ethnicity as "the 
shared identity or similarity of a group of people on the basis of one or more factors", which may include a common geographic origin, language, religion or

291 cultural tradition, and that identity is self-perceived. Consistent with this

292 definition, nearly half of our respondents (44\%) chose more than one descriptor

293 to describe ethnicity, most commonly country of birth and region of ancestry. In

294 this respect, pregnant women reflect expert opinion that ethnicity definitions are

295 subjective, multi-faceted and fluid ${ }^{13}$. The apparent inability to succinctly classify

296 ethnicity mirrors a study that identified over 100 ways to describe ethnicity 19.

297 Furthermore, this study identified for the first time that that how pregnant

298 women understand ethnicity varies according to their self-reported ethnic 299 group. We found that some ethnic groups identify primarily with country of

300 birth, while others describe ethnicity preferentially in terms of religion, physical 301 appearance or language. This further undermines the validity of self-reported 302 ethnicity as a biological variable that can be reliably measured, and for which 303 there can be robust mathematical adjustment.

305 Country of birth - while widely used as a surrogate for ethnicity - was not found 306 to be a reliable representation of women's ethnic group in this cohort. Even for 307 women who chose country of birth as a factor to describe ethnicity, the agreement between their self-reported ethnicity and country of birth was only fair. While women's country of birth is an important variable to collect as it may

311 immigrant women ${ }^{9,20}$, our study highlights that country of birth cannot be 312 considered a reliable measure of biological variation between different ethnic

315 This study adds to existing concerns about the physiological basis for adjusting 316 birthweight standards by different ethnic groups. Many ethnic groups with

317 smaller babies are also at higher risk of perinatal disadvantage, and

318 customisation by ethnicity may therefore mask increased perinatal risks. In

319 Australia, infants of Aboriginal and Torres Strait Islander mothers are twice as

320 likely to born $\mathrm{SGA}^{13}$, but are also at higher risk of preterm birth and perinatal 321 mortality ${ }^{21}$. Similar findings have been shown in the USA for infants of Black and 
322 Hispanic women ${ }^{7,22}$. This suggests that infant smallness in these ethnic groups is 323 more likely to be pathological than constitutional, and may be due to differences 324 in socio-demographic, nutritional and environmental exposures that adversely 325 affect fetal growth. Furthermore, the Intergrowth 21 Fetal Longitudinal Growth

326 Study demonstrated very similar fetal growth in 8 diverse ethno-geographic

327 study sites where pregnant women were free from demographic, nutritional, 328 environmental or socio-economic mediated health disadvantage ${ }^{23}$. To normalise 329 small babies in disadvantaged populations through customisation runs the risk 330 of misclassifying genuinely growth-restricted babies as 'constitutionally small'. Strengths and limitations

334 Strengths of the study include the large sample size in a multicultural population, 335 and collecting information about the woman's partner and their parents to 336 inform expected ethnic mix of the fetus, arguably the most important variable.

337 Furthermore, this study reports women's own understanding of ethnicity and 338 how this varies according to self-identified ethnicity, which has not previously 339 been reported.

341 This study had several limitations. Firstly, logistic constraints meant that women 342 requiring an interpreter were excluded. Nevertheless, the study population 343 included many women who spoke English as a second language, and this 344 proportion was equivalent to that of our hospital population. Secondly, the term 345 'region of ancestry' is unclear. Participants said that they interpreted 'region of 346 ancestry' to be their parents' or grandparents' generation, while another said it was "as long as you can remember". This ambiguity may have resulted in an 348 overuse of this ethnic descriptor. Thirdly, Australia is one of the most ethnically 349 diverse countries in the world, so the findings of this study may not be

352 This study did not explore how health professionals defined ethnicity, which 353 could be explored in future studies. This would be beneficial as health 354 professionals themselves may make these judgements if they were to use ethnic- 
specific growth charts. Additionally, future studies could compare genetic ancestry with self- reported ethnicity. This would likely unmask further complexities, given the degree of genetic admixture identified in other studies, one finding that $17 \%$ of subjects had genetics from at least two continents ${ }^{17}$.

\section{Interpretation}

This study confirms the complexity of defining ethnicity in contemporary multicultural settings, with $13 \%$ of participants being unable to categorise themselves according to the GROW classification. Self-reported ethnicity is unreliable, concepts of ethnicity vary by ethnic group and country of birth is a poor descriptive surrogate. We suggest that maternal self-reported ethnicity is an unreliable measure with which to adjust expectations of fetal growth.

\section{Conclusion}

Maternal self-report of ethnicity is neither feasible nor accurate. Pregnant women's interpretation of 'ethnicity' is highly variable with significant differences observed between different ethnic groups. Ethnic diversity within families, coupled with contemporary migration trends, make self-reported ethnicity - using the options presented in the GROW customisation model - an unreliable measure in a multicultural antenatal population. We suggest that including ethnicity in customisation models clouds, rather than clarifies, interpretation of fetal growth, and should be undertaken with caution.

\section{Acknowledgements}

We would like to acknowledge the patients and staff at MHW, in particular all of those involved in the Fetal Longitudinal Assessment of Growth Study.

\section{Disclosures of interest}

We have no disclosures of interest to declare. The ICMJE disclosure forms are available as online supporting information.

\section{Funding Declarations}


388 There has been no external funding for this study and we have no financial

389 interests to declare

\section{Contribution to authorship}

391 Lockie EB: Developed idea for the project, planned project, completed ethics

392 application, conducted questionnaires, wrote manuscript.

393 McCarthy EA: Contributed to development of project, piloted questionnaire,

394 drafted and reviewed manuscript

395 Hui L: Contributed to development of project, piloted questionnaire, drafted and

396 reviewed manuscript

397 Churilov L: Responsible for statistical advice and analysis, drafted and reviewed

398 manuscript

399 Walker SP: Developed and supervised project, piloted questionnaire, drafted and

400 reviewed manuscript

401

402 Ethics approval

403 Ethics approval for this study was obtained from the Mercy Health Human

404 Research Ethics Committee (R16/11, 26 th May 2016), and written informed

405 consent was obtained from all participants.

406

407 References

408 1. Gardosi J, Madurasinghe V, Williams M, Malik A, Francis A. Maternal and

409 fetal risk factors for stillbirth: population based study British Medical Journal.

$410 \quad 2013 ; 346: 1-14$.

411 2. Hirst JE, Villar.J., Victora CG, Papageorghiou AT, Finkton D, Barros FC, et

412 al. The antepartum stillbirth syndrome: risk factors and pregnancy conditions

413 identified from the INTERGROWTH-21st project. Bjog. 2016.

$4143 . \quad$ Mendez-Figueroa H, Truong V, Pedroza C, Khan AM, Chauhan SP. Small-

415 for-gestational-age infants among uncomplicated pregnancies at term: a

416 secondary analysis of 9 Maternal-Fetal Medicine Units Network studies.

417 American Journal of Obstetrics \& Gynecology. 2016;215(5):628.e1-.e7.

418 4. Murray E, Fernandes M, Fazel M, Kennedy SH, Villar J, Stein A. Differential

419 effect of intrauterine growth restriction on childhood neurodevelopment: a

420 systematic review. Bjog. 2015;122(8):1062-72. 
421 5. Saenger P, Czernichow P, Hughes I, Reiter EO. Small for gestational age:

422 short stature and beyond. Endocrine Review. 2007;28(2):219-51.

423 6. Gestation Network. GROW centile calculator, Australia v5.7.5.2.

424 7. Kramer MS, Ananth CV, Platt RW, Joseph KS. US Black vs White disparities

425 in foetal growth: physiological or pathological? International journal of

426 epidemiology. 2006;35(5):1187-95.

427 8. Bryant AS, Worjoloh A, Caughey AB, Washington AE. Racial/ethnic

428 disparities in obstetric outcomes and care: prevalence and determinants.

429 American Journal of Obstetrics \& Gynecology. 2010;202(4):335-43.

430 9. Almeida LM, Caldas J, Ayres-de-Campos D, Salcedo-Barrientos D, Dias S.

431 Maternal healthcare in migrants: a systematic review. Maternal Child Health 432 Journal. 2013;17(8):1346-54.

433 10. Bergin H, Walker S, Wood G, Hui L, editors. Successful implementation of

434 new management guidelines and a specialized clinic for hepatitis B positive

435 pregnant women. Royal Australian and New Zealand College of Obstetricians and

436 Gynaecologists 2016 Annual Scientific Meeting; 2016 October 16-19; Perth,

437 Australia.

438 11. Nesvadba N. Mercy Public Hospitals Inc. (MPHI) Demographic profile

439 2015/16. In: Lockie E, editor. 2016.

440 12. Australian Health Survery: First Results, 2011-12. In: Statistics ABo,

441 editor. 2012.

442 13. Li Z, Zeki R, Hilder L, Sullivan EA. Australia's mothers and babies 2011. 28

443 ed: Australian Institute of Health and Welfare; 2011.

444 14. Office of National Statistics. Parents' Country of Birth, England and Wales:

445 20142015. Available

446 from: https://www.ons.gov.uk/peoplepopulationandcommunity/birthsdeathsan

447 dmarriages/livebirths/bulletins/parentscountryofbirthenglandandwales/2015-

$448 \quad \underline{08-27}$.

449 15. Australian Bureau of Statistics. Family Formation: Cultural diversity in

450 marriages 2000 [Available

451 from: http://www.abs.gov.au/AUSSTATS/abs@.nsf/2f762f95845417aeca25706

452 c00834efa/c414ec2a595eb029ca2570ec000e2817! OpenDocument. 
453 16. Office of National Statistics. 2011 census analysis: what does the 2011

454 census tell us about inter-ethnic relationships?2014. Available

455 from: http://www.ons.gov.uk/peoplepopulationandcommunity/birthsdeathsan

456 dmarriages/marriagecohabitationandcivilpartnerships/articles/whatdoesthe20

457 11censustellusaboutinterethnicrelationships/2014-07-03.

458 17. Banda Y, Kvale MN, Hoffmann TJ, Hesselson SE, Ranatunga D, Tang H, et

459 al. Characterizing Race/Ethnicity and Genetic Ancestry for 100,000 Subjects in

460 the Genetic Epidemiology Research on Adult Health and Aging (GERA) Cohort.

461 Genetics. 2015;200(4):1285-95.

462 18. Australian Bureau of Statistics. Australian standard classification of

463 cultural and ethnic groups (ASCCEG) 2011 [updated 2016 July 18. Available

464 from: http://www.abs.gov.au/AUSSTATS/abs@.nsf/Latestproducts/1249.0Main

465 Features12016?opendocument\&tabname=Summary\&prodno=1249.0\&issue $=20$

$466 \quad 16 \&$ num $=\& v i e w=$.

467 19. Ma IW, Khan NA, Kang A, Zalunardo N, Palepu A. Systematic review

468 identified suboptimal reporting and use of race/ethnicity in general medical

469 journals. J Clin Epidemiol. 2007;60(6):572-8.

470 20. Dahlen HG, Schmied V, Dennis C, Thornton C. Rates of obstetric

471 intervention during birth and selected maternal and perinatal outcomes for low

472 risk women born in Australia compared to those born overseas. BMC Pregnancy

473 Childbirth. 2013;13(100):1-9.

474 21. Ballestas T, on behalf of the Perinatal and Infant Mortality Committee of

475 Western Australia The 14th report of the perinatal and infant mortality

476 committee of Western Australia for deaths in the triennium 2008-2010. In:

477 Government of Western Australia DoH, editor. 2014.

478 22. Alexander GK, M.; Bader, D.; Carlo, W.; Allen, M.; Mor, J. US

479 birthweight/gestational age-specific neonatal mortality: 1995-1997 for Whites,

480 Hispanics and Blacks. Pediatrics 2003;111(1):61-6.

481 23. Villar J, Papageorghiou AT, Pang R, Ohuma EO, Cheikh Ismail L, Barros FC, 482 et al. The likeness of fetal growth and newborn size across non-isolated

483 populations in the INTERGROWTH-21st Project: the Fetal Growth Longitudinal

484 Study and Newborn Cross-Sectional Study. The Lancet: Diabetes \&

485 Endocrinology. 2014;2:781-92.

This article is protected by copyright. All rights reserved 


\section{Figures, tables \& appendices}

Figure 1. Descriptors for the term 'ethnicity' chosen by an Australian antenatal population

491 Figure 2. Factors chosen to describe ethnicity by women who selfidentified as Australian, Indian or Chinese

493

494

495 496 Table 1: Percentage of ethnicity (participants and family members) according to the GROW options Appendix S1: Australian GROW ethnicity list Appendix S2: Survey

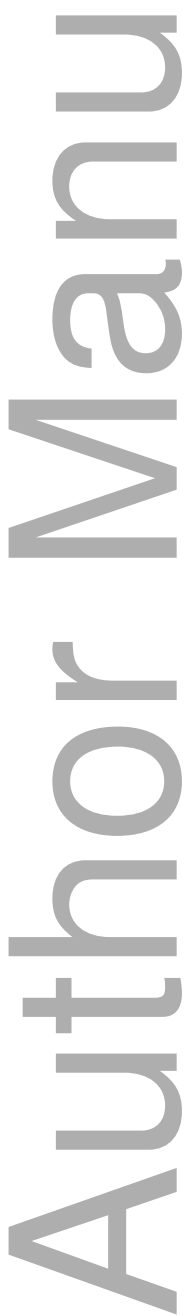


Table 1: Percentage of ethnicity (participants and family members) according to the GROW options.

\begin{tabular}{|c|c|c|c|c|c|c|}
\hline & Participant & Her & Her & Father of & FOB & FOB \\
Baby & father \\
mother & & & 93 & 91 \\
\hline Able to select a GROW option (\%) & 87 & 93 & 91 & 84 & 7 & 9 \\
\hline Total (\%) who could not choose & 13 & 7 & 9 & 16 & 3 \\
\hline 1. Unknown & 0 & 1 & 2 & 1 & 2 & 2 \\
\hline 2. Mixed & 11 & 4 & 5 & 12 & 2 \\
\hline 3. Other* & 2 & 2 & 3 & 4 & 3 \\
\hline
\end{tabular}

*Other: Argentina, Chile, Sri Lanka, Libya, Serbia, Zimbabwe, Mauritius, Congo, Macedonia

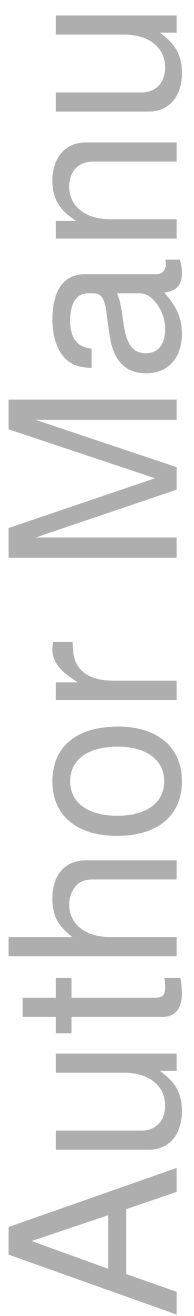


Figure 1. Descriptors for the term 'ethnicity' chosen by an Australian antenatal population
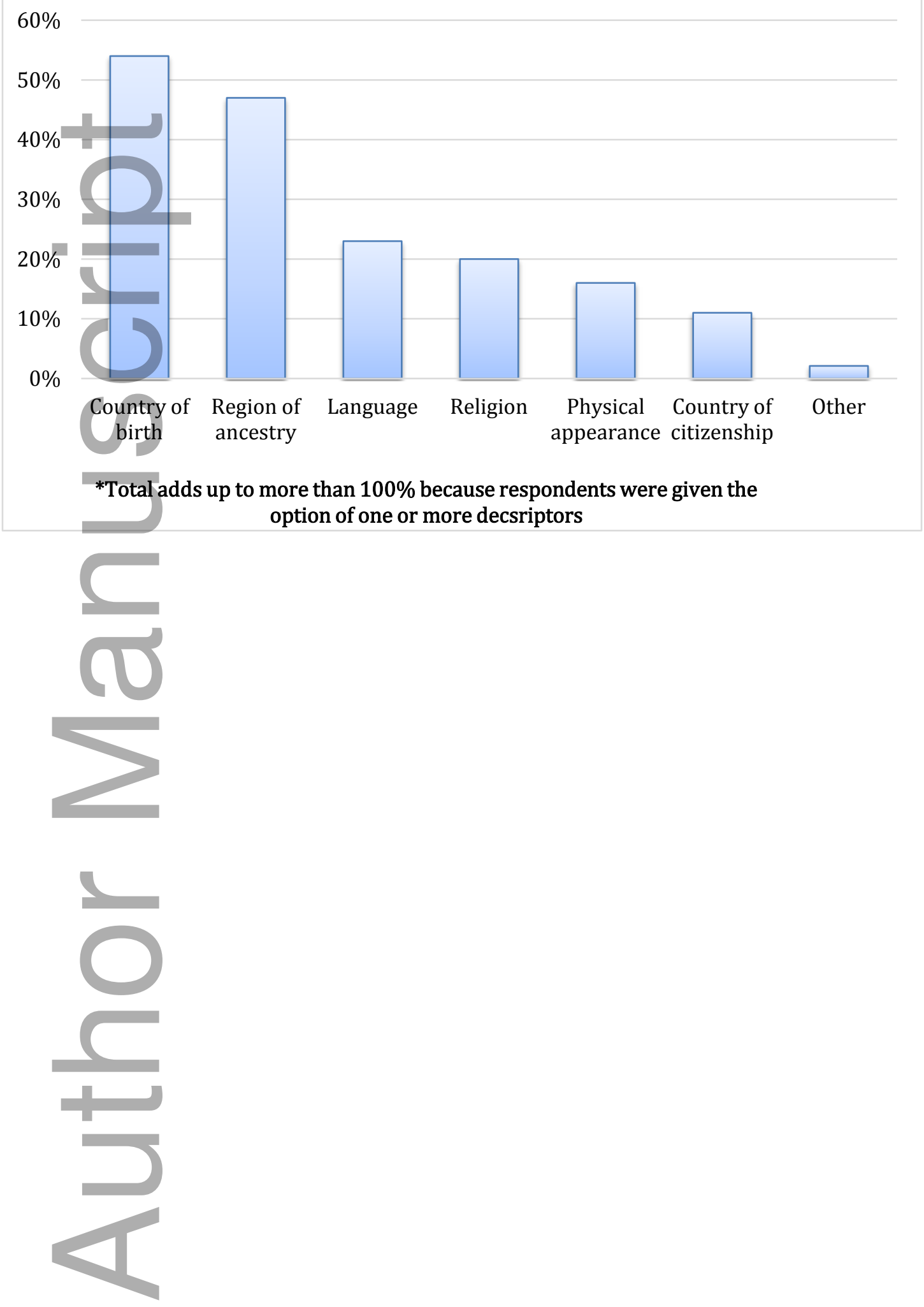

This article is protected by copyright. All rights reserved 
Figure 2. Factors chosen to describe ethnicity by women who self-identified as Australian, Indian or Chinese
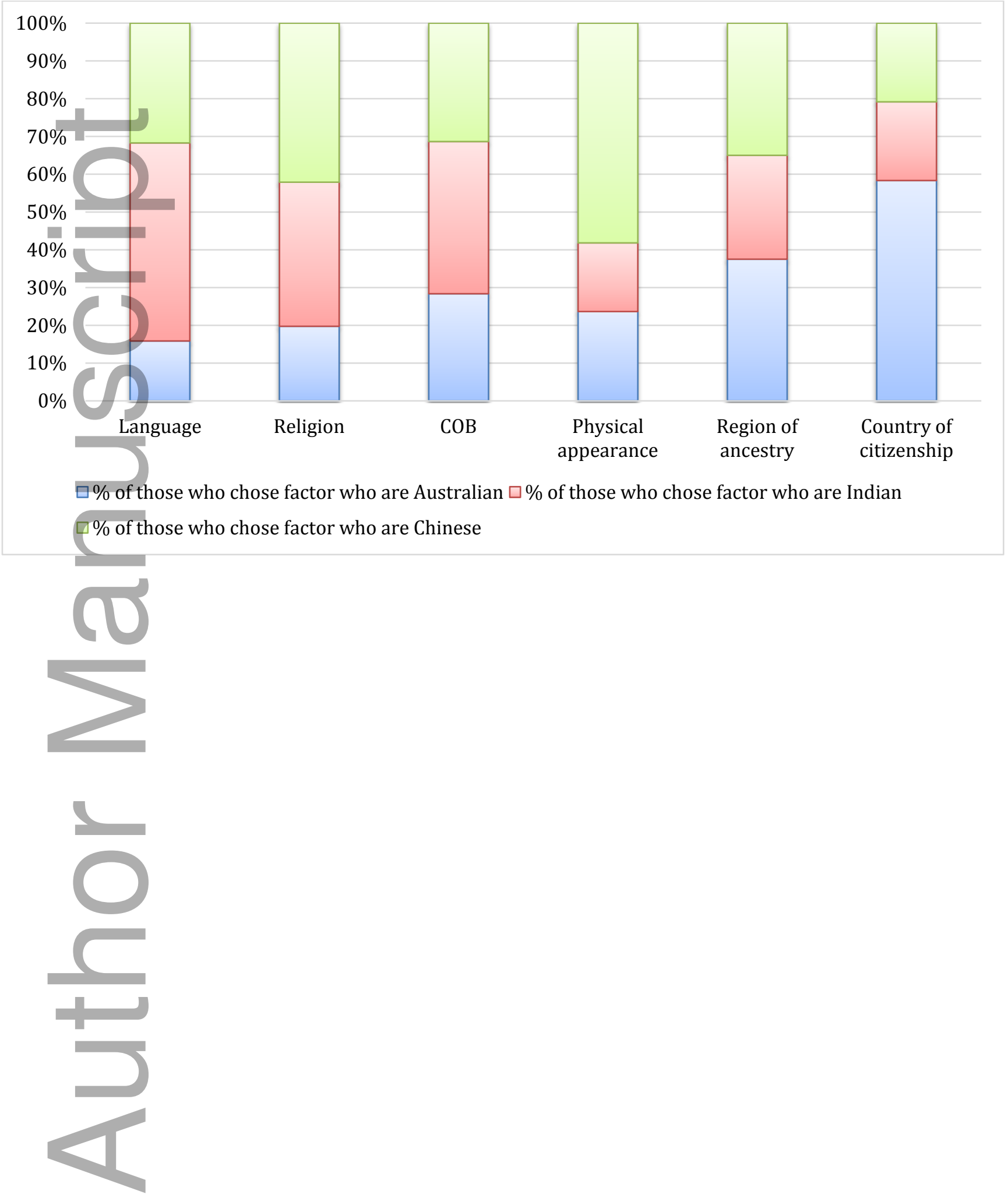

This article is protected by copyright. All rights reserved 


\section{University Library}

\section{- M M I N E R VA \\ A gateway to Melbourne's research publications}

Minerva Access is the Institutional Repository of The University of Melbourne

Author/s:

Lockie, E;McCarthy, EA;Hui, L;Churilov, L;Walker, SP

Title:

Feasibility of using self-reported ethnicity in pregnancy according to the gestation-related optimal weight classification: a cross-sectional study

Date:

2018-05-01

Citation:

Lockie, E., McCarthy, E. A., Hui, L., Churilov, L. \& Walker, S. P. (2018). Feasibility of using self-reported ethnicity in pregnancy according to the gestation-related optimal weight classification: a cross-sectional study. BJOG-AN INTERNATIONAL JOURNAL OF OBSTETRICS AND GYNAECOLOGY, 125 (6), pp.704-709. https:// doi.org/10.1111/1471-0528.14825.

Persistent Link:

http://hdl.handle.net/11343/293346 